\title{
Assessing the hydrological impacts of agricultural changes upstream of the Tunisian World Heritage sea-connected Ichkeul Lake
}

\author{
J. AOUISSI ${ }^{1}$, Z. LILI CHABAANE ${ }^{1}$, S. BENABDALLAH ${ }^{2}$ \& C. CUDENNEC ${ }^{3}$ \\ 1 University Carthage-Institut National Agronomique de Tunisie, 43 Av. Charles Nicole, Cité Mahrajène, 1082 Tunis, \\ Tunisia \\ jalelaouissi@yahoo.fr; zohra.lili.chabaane@gmail.com \\ 2 Center for Water Research and Technologies, Borj Cedria Ecopark, PO Box 273 Soliman 8020, Tunisia \\ 3 Agrocampus Ouest, INRA, UMR1069, Soil Agro and hydroSystem, F-35000 Rennes, France
}

\begin{abstract}
The impact of changes in agricultural land use and practices as a controlling driver of hydrologic response and as a source of diffuse pollution, are studied in the Joumine River basin, discharging into the Ichkeul Lake, northern Tunisia, a UNESCO World Heritage site since 1979. The lake is characterized by a very specific hydrological functioning based on a seasonal alternation of water levels and salinity through its link to the Mediterranean Sea. Three Landsat images, in situ surveys and SWAT modelling were used to simulate and assess streamflows and nitrate loads under retrospective land uses.
\end{abstract}

Key words land-use change; Joumine basin; SWAT model; nitrates; spatial analysis; remote sensing

\section{INTRODUCTION}

Land-use and land-cover changes often have significant impacts on water quantity and quality, which need to be assessed to support management strategies. Further, interdependent changes of agricultural practices, land use and cover, and hydrology have to be better analysed (Montanari et al. 2013), especially in rapidly changing and water-stressed areas such as the Mediterranean region (Cudennec et al. 2007).

The Ichkeul Lake ecosystem has been inscribed on three international lists: as a biosphere reserve in 1977 (MAB-UNESCO Convention), a UNESCO World Heritage site in 1979, and a worldwide notable wetland (RAMSAR Convention) in 1980. Considering the main Joumine River basin within the lake watershed, multi-date satellite images (Landsat 1986, 2002 and 2010) were used to detect and characterize long-term retrospective land-use changes; surveys allowed us to describe the associated farming practices; and a SWAT modelling approach was used to synthesize knowledge and further assess the hydrological impacts.

\section{MATERIALS AND METHODS}

The Ichkeul Lake watershed includes the drainage basins of the Joumine, Ghezala, Melah, Sejnane, Tine and Douimis rivers (Fig. 1). Due to their inflow, during winters the lake salinity decreases while the water level increases. Excess water then naturally flows from the Ichkeul Lake towards the intermediate Bizerte Lake, itself connected to the Mediterranean Sea. In summer, the rivers dry up and the intense evaporation cause a drop in water level in Ichkeul Lake, which inverts the flow from the Bizerte Lake towards the Ichkeul Lake, causing a rise in salinity. In this study, we focused on the most important Joumine River basin of the Ichkeul Lake watershed (Fig. 1). It has a sub-humid climate (Slimani et al. 2007, Baccour et al. 2012, Feki et al. 2012) and a rural environment, draining an area of $418 \mathrm{~km}^{2}$, with elevation ranging between 35 and $716 \mathrm{~m}$ above sea level. The average annual precipitation was $750 \mathrm{~mm}$ for the period 1990-2010, with an average rainfall of $125 \mathrm{~mm}$ in December. The average temperature ranges from $25^{\circ} \mathrm{C}$ in August to $8^{\circ} \mathrm{C}$ in January. The dominant soils are sandy-clay and silty-clay soils. Soil maps and typical soil profiles were produced by using studies of the Tunisian soil authority (Ministère de l'Agriculture 2002). Approximately $68 \%$ of the catchment area is devoted to cereal crops, $30 \%$ to sunflower crops and pasture, and $2 \%$ to scattered rural settlements. In situ surveys conducted indicate that the amount of $\mathrm{N}$ fertilizer used for wheat crop is $118 \mathrm{~N} \mathrm{ha}^{-1}$ year- $^{-1}$ (Aouissi et al. 2013, 2014). 


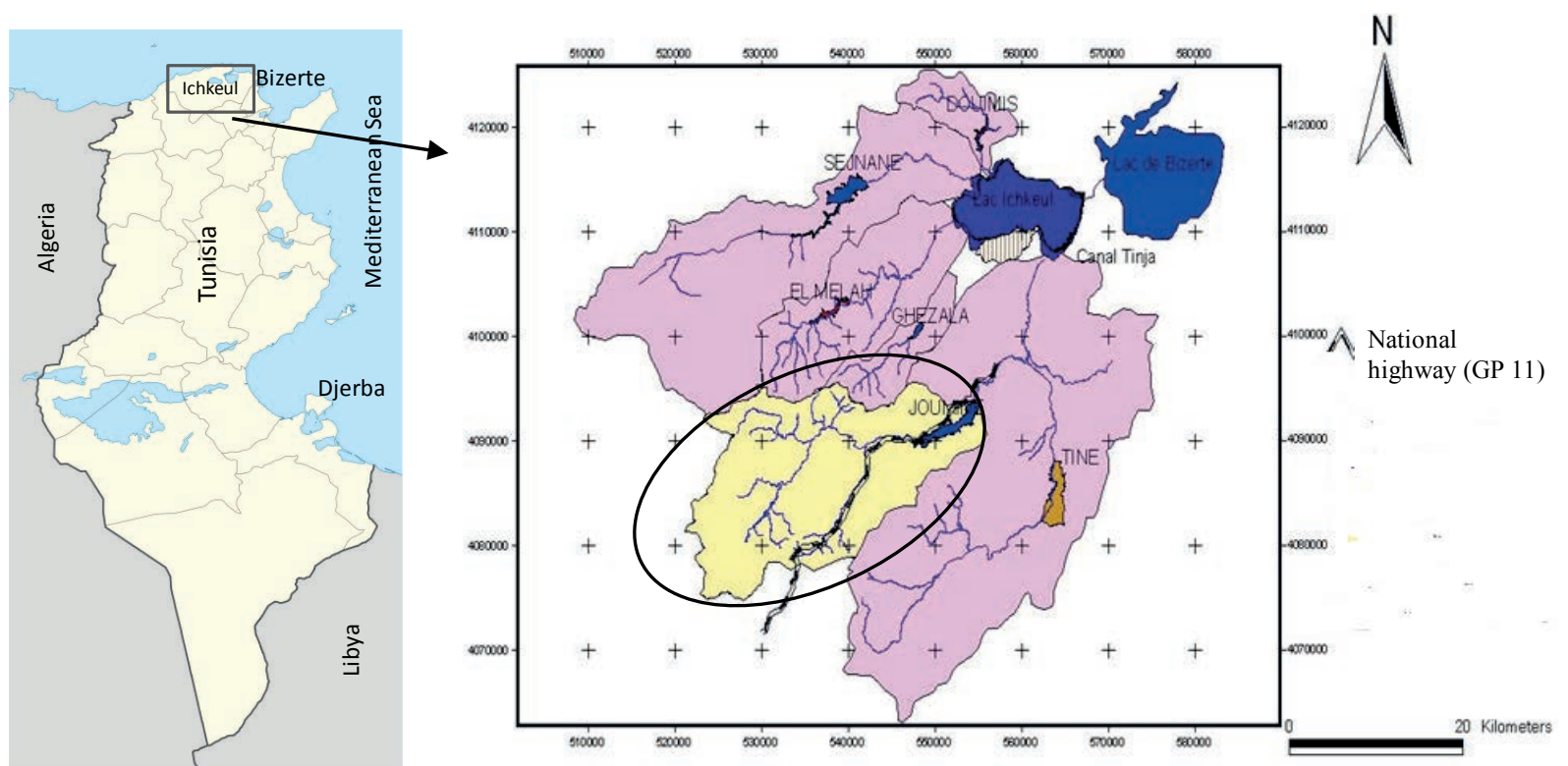

Fig. 1 Study area location.

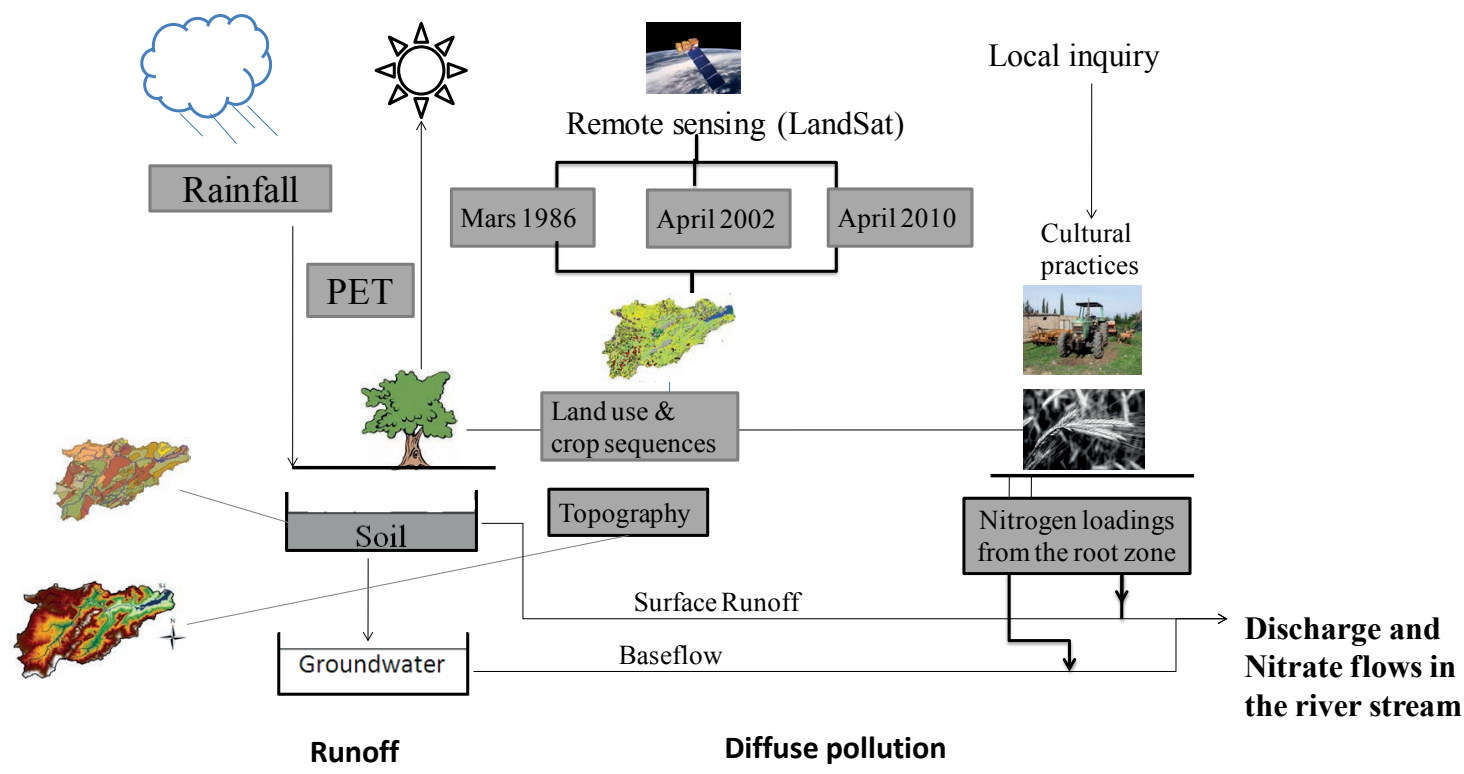

Fig. 2 Diagram showing the SWAT model application (adapted from Laurent and Ruelland 2011).

The SWAT model is a distributed hydrological model, developed by the United States Department of Agriculture, to assess and predict the impact of land management practices on water, sediment and agricultural chemicals yields in large complex watersheds with varying soils, land use and management conditions over long periods of time (Arnold et al. 1998, Neitsch et al. 2010). We used the SWAT model (Fig. 2) in conjunction with remote sensing techniques, which were applied to assess the retrospective land-use patterns of the Joumine basin. Three Landsat images, dated March 1986, April 2002 and April 2010, were employed for evaluating the land-use evolution, the spring season being the period for vegetation development. The basin is mostly covered by agricultural land. Thus, the distinction between crops during satellite image processing is very difficult. Landsat imagery was processed to emphasize land use using Envi 4.7 software. The Landsat images acquired on March 1986 and April 2002 were used within a non-supervised classification that is based on spectral information and spatial data available in the Regional 
Commissary for Agricultural Development of Bizerte for identifying land uses. Supervised classification was used to process the April 2010 Landsat image based on training sites and published maps. To minimize classification errors, a mask was applied on the forest, garrigue and water.

\section{RESULTS AND DISCUSSION}

\section{Results of image processing}

For the March 1986 and April 2002 images, classification shows a good result compared to published maps and in situ surveys. Figure 4 shows the classification results of the March 1986 image. The classification results of the April 2010 image show a good precision with a 90\% kappa coefficient. The cereal culture occupied more than $50 \%$ of the Joumine basin area, increasing from $50 \%$ in 1986 to $70 \%$ in 2010 over the garrigue area (Figs 3, 4(a) and 4(b)). The rural housing gradually expanded from $0.7 \%$ in 1986 to $2 \%$ in 2010 over the agriculture area, while the water surface was relatively constant. Figure 4(b) shows a land-cover map produced by processing the Landsat image of April 2010. Three dominant crops are determined and are analysed using in situ surveys. These cultures are characterized by an application of large amounts of $\mathrm{N}$ fertilizers (Aouissi et al. 2014).

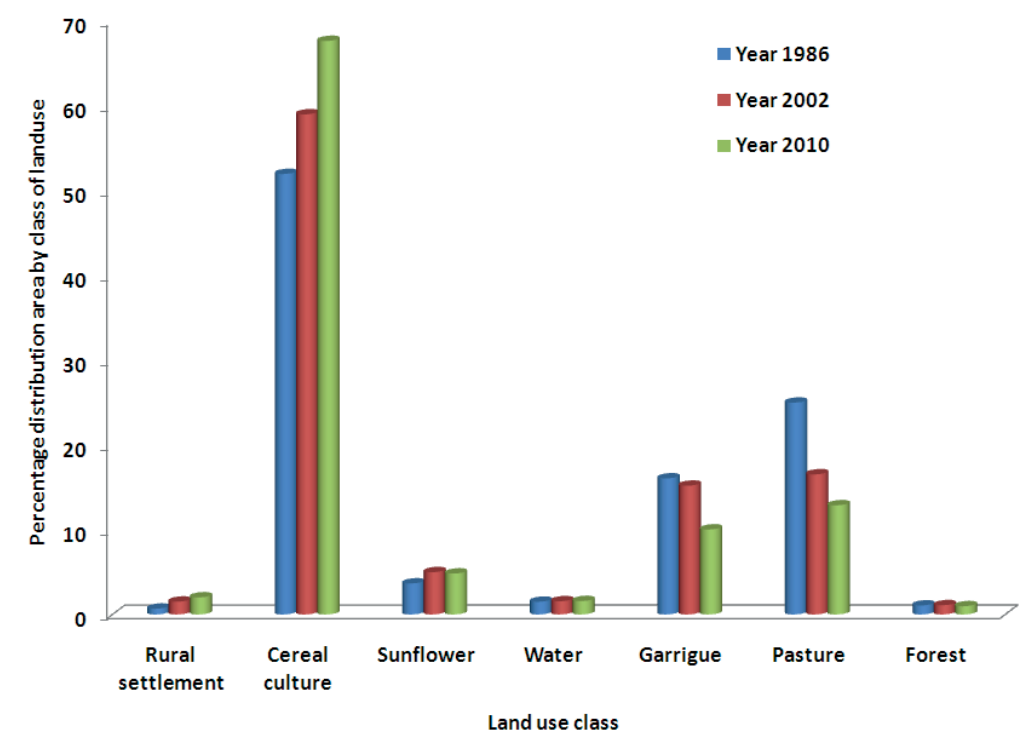

Fig. 3 Evolution of land use in the Joumine basin from 1986 to 2010.



(a)

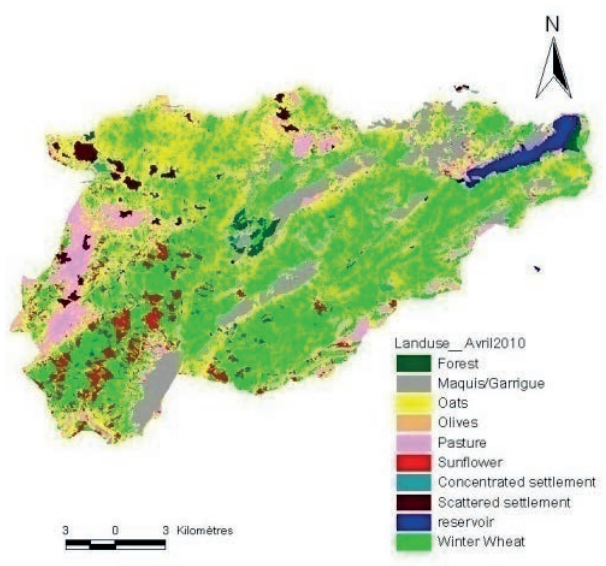

Fig. 4 Land use on March 1986 (a) and April 2010 (b).

(b) 


\section{Impacts of land-use change on streamflow and nitrate simulations}

The model was calibrated using the recent land-use map over the simulation period of 1990 to 2003. The simulated and measured monthly streamflow values are compared in Fig. 5. The model reproduces well the observed trend, especially for the peak flow, with a general overestimation especially for dry years, as is the case for 1994 and 2000. The Nash-Sutcliffe Efficiency (NSE) values are 0.66, 0.67 and 0.68 when using the land-use maps of 1986, 2002 and 2010, respectively. The use of the different land-use maps did not significantly affect the hydrological response in terms of streamflow. Change has more impacted the agricultural practices rather than the land-use classes, which explains the similar hydrologic response compared to the observed flows.

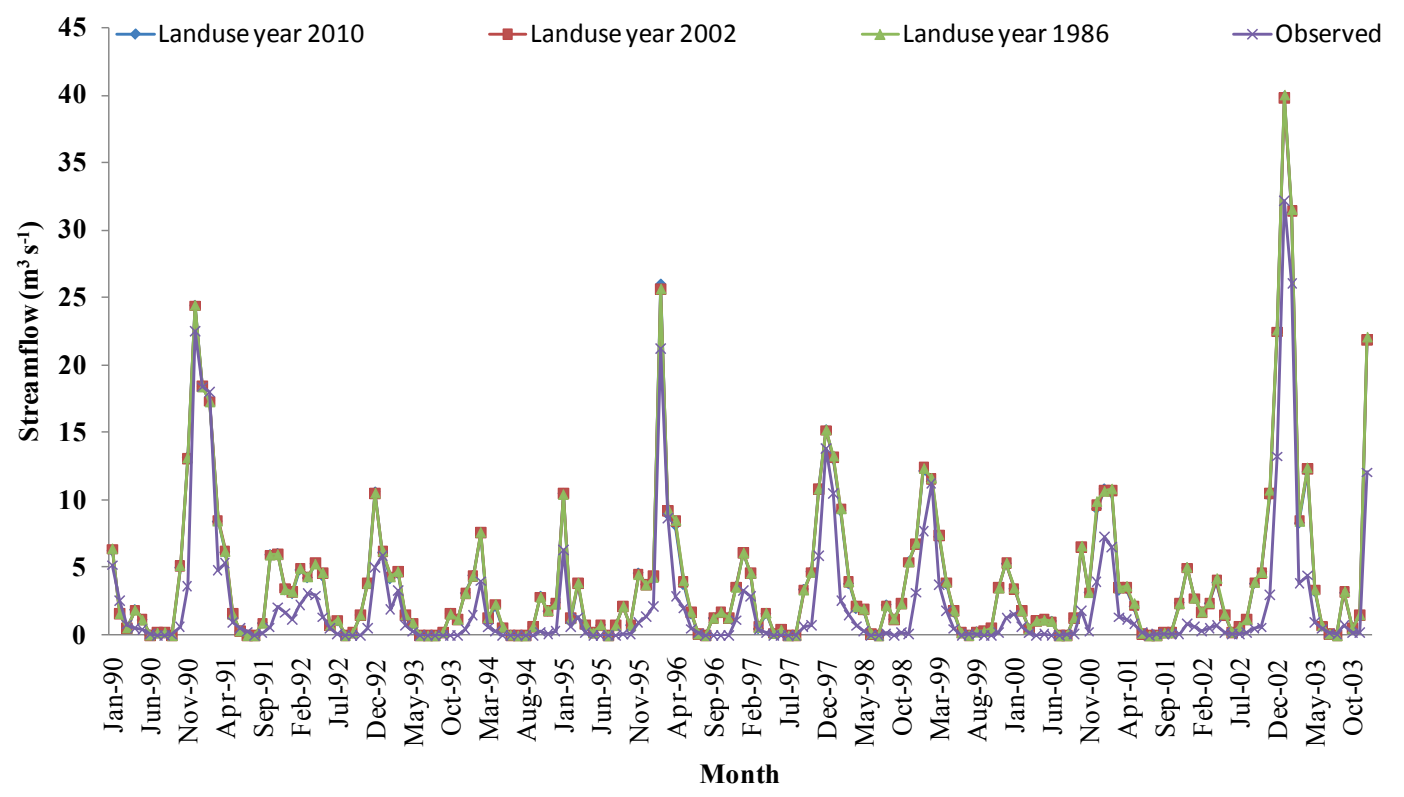

Fig. 5 Comparison between the measured and simulated monthly streamflows for the different land uses.
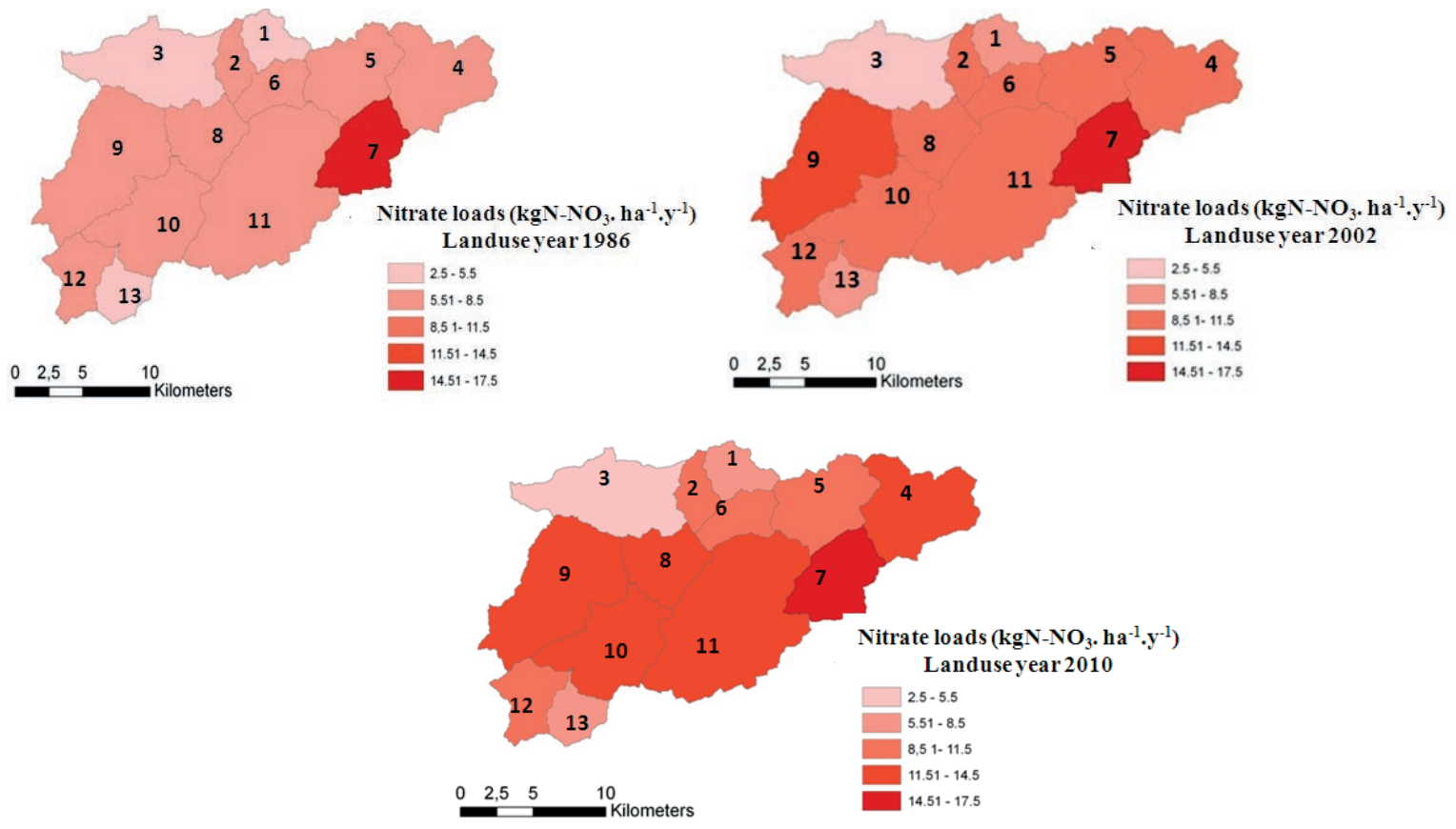

Fig. 6 Spatial distribution of nitrate fluxes across sub-basins of the Joumine basin. 
The simulation of mean $\mathrm{N}^{-\mathrm{NO}_{3}}$ concentrations are 1.6, 2 and $2.6 \mathrm{mg} \mathrm{L} \mathrm{L}^{-1}$ when considering land-use maps of 1986, 2002 and 2010, respectively, over the 1990-2003 period. Aouissi et al. (2014) show that the daily ${\mathrm{N}-\mathrm{NO}_{3}}_{3}$ concentrations measured and simulated at the outlet of the Joumine basin ranged from 0 to $5 \mathrm{mg} \mathrm{L}^{-1}$. The land-use change greatly affected the nitrate fluxes during the simulation period from 1986 to 2010 (Fig. 6). Marked variability in nitrate loads appears among different land-use maps for the same cultural practices (Fig. 6). Pasture and garrigue classes were transformed into agricultural land from 1986 to 2010. The simulation of nitrate loads shows that the highest risk of leaching is with winter wheat and oats, and the lowest risk with pasture. It is noted that pastures are not fertilized in this area.

The spatial distribution of nitrate fluxes led to determine the significant contributing areas of the nitrate load (Fig. 6). Sub-basins 9, 8, 7 and 6 are the main contributing areas of nitrate loads, using the land-use maps of 2002 and 2010 (Fig. 6). They are dominated by the wheat culture, which is a major consumer of chemical fertilizers.

\section{CONCLUSION}

This study tested the effect of land-cover change on the streamflow and nitrate loads within the Joumine River basin, a major part of the unique Ichkeul Lake ecosystem. The SWAT model is a useful tool to integrate retrospective knowledge and trends, to understand interactions between climate, soils and agricultural practices, and to assess the sensibility to land changes and spatial arrangements. Results show that the nature of observed land-use change does not have any strong impact on the hydrological response; while the increase of the area devoted to cereal crops, which was accompanied by an increase in applied fertilizer amounts, had an impact on the nitrate concentrations in the surface water.

Acknowledgements This work was performed under the project "Integrated Water Management of the Ichkeul River basin taking into account the preservation of the Ichkeul ecosystem" funded by CIDA and by Wetlands International.

\section{REFERENCES}

Aouissi J., et al. (2013) Sensitivity analysis of SWAT model to the spatial rainfall distribution and watershed subdivision in streamflow simulations in the Mediterranean context: A case study in the Joumine watershed, Tunisia. Modeling, Simulation and Applied Optimization IEEE 6, doi:10.1109/ICMSAO.2013.6552706.

Aouissi J., et al. (2014) Modeling water quality to improve agricultural practices and land management in a Tunisian catchment using the Soil and Water Assessment Tool. Journal of Environmental Quality 43(1), 18-25, doi:10.2135/JEQ2011.0375.

Arnold, J. G., et al. (1998) Large area hydrologic modeling and assessment part I: model development. J. Am. Water Resour. As. 34(1), 73-89.

Baccour, H., Slimani, M. and Cudennec, C. (2012) Etude synoptique conjointe des structures spatiales de l'évapotranspiration et de variables climatiques corrélées en Tunisie. Hydrological Sciences Journal 57(4), 818-829, doi: 10.1080/02626667.2012.672986

Cudennec, C, Leduc C. and Koutsoyiannis D. (2007) Dryland hydrology in Mediterranean regions: A review. Hydrological Sciences Journal 52(6), 1077-1087, doi:10.1623/hysj.52.6.1077.

Feki H., Slimani M. and Cudennec C. (2012) Incorporationg elevation in rainfall interpolation in Tunisia using geostatistical methods. Hydrological Sciences Journal 57(7), 1294-1314, doi:10.1080/02626667.2012.710334.

Laurent, F. and Ruelland D. (2011) Assessing impacts of alternative land use and agricultural practices on nitrate pollution at the catchment scale. Journal of Hydrology409, 440-450.

Ministère de l'Agriculture (2002) Cartes agricoles de la Tunisie. Ministère de l'Agriculture, Tunis, Tunisia.

Montanari A., et al. (2013) "Panta Rhei - Everything Flows": Change in hydrology and society - The IAHS Scientific Decade 2013-2022. Hydrological Sciences Journal 58(6), 1256-1275, doi:10.1080/02626667.2013.809088

Neitsch, S.L., et al. (2010) Soil and Water Assessment Tool Input/Output File Documentation Version 2009.

Slimani M., Cudennec C. and Feki H. (2007) Structure du gradient pluviométrique de la transition Méditerranée-Sahara en Tunisie: Déterminants géographiques et saisonnalité. Hydrological Sciences Journal 52(6), 1088-1102, doi:10.1623/hysj.52.6.1088. 